\title{
Studies on Intermediates Involved in the Syntheses of Pentaerythritol and Related Alcohols. VI.* Base-catalyzed Retro Condensation Reactions of Some $\alpha$-Hydroxymethyl Carbonyl and Nitro Compounds
}

\author{
JAN-ERIK VIK**
}

Department of Organic Chemistry, Chalmers University of Technology and University of Göteborg, Fack, S-402 20 Göteborg 5, Sweden

The base-catalyzed retro aldol condensation reactions of some aldehydic intermediates in the syntheses of pentaerythritol and related alcohols have been investigated kinetically. Rate constants for these reactions, involving the splitting off of formaldehyde, have been obtained for the compounds 2,2-bis(hydroxymethyl)-3-hydroxypropanal, 3-hydroxy-2-hydroxymethyl-2methylpropanal, 2-ethyl-3-hydroxy-2-hydroxymethylpropanal, and 2,2-dimethyl-3-hydroxypropanal. These aldehydes were all found to undergo retro aldol reaction in aqueous solution at rather low concentration of sodium hydroxide. Under the conditions used, the re. actions did not proceed beyond the liberation of one molecule of formaldehyde per molecule of starting material. 2,3-Dihydroxypropanal, having one $\alpha$-hydrogen, released almost no formaldehyde at $20^{\circ} \mathrm{C}$ in $0.010 \mathrm{M} \mathrm{NaOH}$. 3-Hydroxy-2-hydroxymethylpropanal, also containing one $\alpha$-hydrogen, gave rise to formaldehyde formation slowly, but, as will be shown in a subsequent paper, probably in an indirect way via another reaction.

For comparison, the corresponding reactions of some other activated, hydroxymethylsubstituted compounds have been investigated also. The ketones 4-hydroxy-3-hydroxymethyl3-methyl-2-butanone, 3-hydroxy-2-hydroxymethyl-2-methyl-1-phenyl-1-propanone, 2,2-bis(hydroxymethyl)-1-tetralone, 2,2-bis(hydroxymethyl)-1-indanone, and 2,3-dihydroxy-1,2-diphenyl-1-propanone also released formaldehyde, the second and the fourth of these compounds giving rise to more than one $\mathrm{mol}$ of formaldehyde per mol of ketone.

* Acta Chem. Scan. B 28 (1974) 325.

** Present address: Perstorp AB, S-284 00 Perstorp, Sweden.
Of the nitro compounds examined, 2-hydroxymethyl-2-nitro-1,3-propanediol, 2-methyl-2nitro-1,3-propanediol, 2-ethyl-2-nitro-1,3-propanediol, and 2-methyl-2-nitro-1-propanol reacted with consumption of hydroxide ion under formation of nitronate ions and one mol of formaldehyde. 2-Nitroethanol and 2-nitro-1. butanol slowly released formaldehyde, but these reactions were not investigated kinetically.

9,9-Bis(hydroxymethyl)fluorene was almost stable in $0.2 \mathrm{M} \mathrm{NaOH}$ at $55^{\circ} \mathrm{C}$.

The reactions were followed by spectrophotometric determination of free formaldehyde according to the method reported by Nash, based on the Hantzsch reaction.

This investigation is part of a series of studies undertaken with the purpose of clarifying, as to rates and mechanisms, the reaction steps involved in the syntheses of polyalcohols by condensation reactions between formaldehyde and low molecular weight aliphatic aldehydes. It is believed that a better knowledge of these reactions will help to indicate which types of side reactions are important under different reaction conditions and how these conditions should be chosen in order to improve the quality and yield of the polyalcohols produced. More specifically, if formaldehyde is used in nearly stoichiometric amounts, retro aldol condensation reactions presumably can be important during the last stages of the syntheses when the concentration of formaldehyde is low. The amounts of intermediate aldehydes still present at this stage and those of their possible

Acta Chem. Scand. B 28 (1974) No. 5 
conversion products formed in side reactions may thus be determined by retro aldol reactions.

Aldol condensation reaction are believed to be generally reversible ${ }^{1}$ and the reversibility has been proven in many cases. ${ }^{2,3}$ In order to examine the rates of those retro aldol condensation reactions which are possible under the conditions of synthesis of pentaerythritol and related alcohols, a suitable method was needed, by means of which the progress of these reactions could be followed. The formaldehyde determination method reported by Nash, ${ }^{4}$ based on the Hantzsch reaction, is almost ideal for the purpose. It allows accurate and relatively rapid determinations of formaldehyde in very dilute aqueous solutions, undisturbed by the presence of most other carbonyl compounds. The procedure utilizes the reaction of formaldehyde with acetylacetone and an ammonium salt with the formation of diacetyldihydrolutidine, which is yellow and has an absorptivity of 8000 at $412 \mathrm{~nm}$. The lutidine derivative is formed rapidly and quantitatively in neutral aqueous solution. Since the preferable reaction conditions are very mild, the starting materials, as was proven for all the compounds examined, neither react to form coloured products nor release additional formaldehyde during the determinations.

The fully $\alpha$-hydroxymethyl-substituted aldehydes, 2,2-bis(hydroxymethyl)-3-hydroxypropanal (I, trimethylolacetaldehyde), 3-hydroxy2-hydroxymethyl-2-methylpropanal (II, dimethylolpropionaldehyde), 2-ethyl-3-hydroxy2-hydroxymethylpropanal (III, dimethylolbutyraldehyde), and 2,2-dimethyl-3-hydroxypropanal (IV, pentaldol), are the immediate precursors of pentaerythritol, trimethylolethane, trimethylolpropane, and neopentylglycol, respectively (Fig. 1).

For both statistical and sterical reasons, these aldehydes were expected to be most susceptible to base-catalyzed retro aldol con-

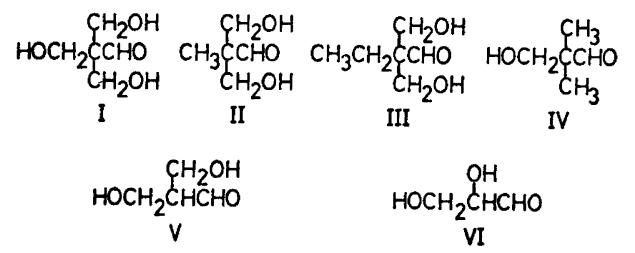

Fig. 1.

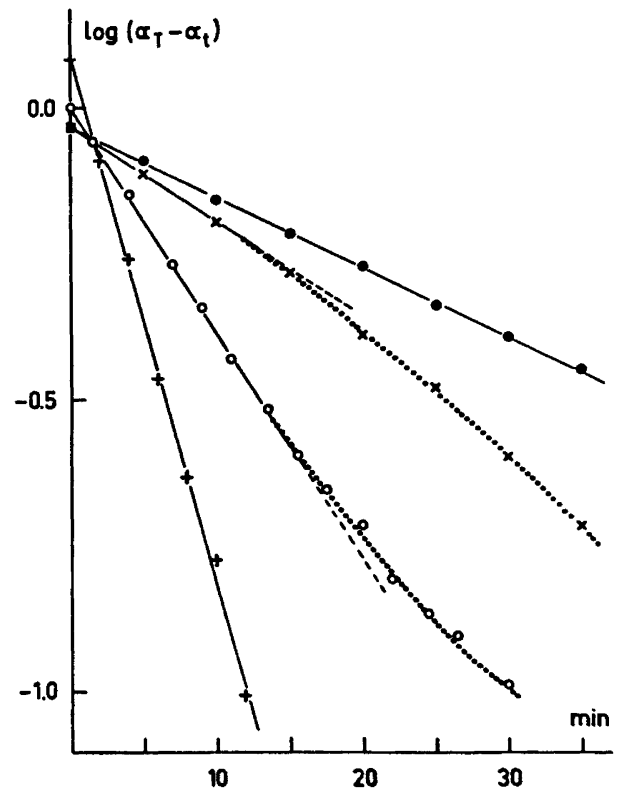

Fig. 2. Pseudo first-order plots for disappearance at $40^{\circ} \mathrm{C}$ of starting materials in terms of absorbance units $\left(\alpha_{T}=\right.$ theoretical maximum absorbance of the equimolar amount of formaldehyde derivative and $\alpha_{t}=$ absorbance at time $t$ actually found for the formaldehyde derivative). + : I in 0.0020 M NaOH; O: III in $0.0050 \mathrm{M} \mathrm{NaOH}$; $X$ : IX in $0.0020 \mathrm{M} \mathrm{NaOH}$, and $\mathrm{OI}$ in $0.010 \mathrm{M} \mathrm{NaOH}$.

densation with resultant loss of formaldehyde and were first examined. When treated in about $5 \times 10^{-4} \mathrm{M}$ solutions with $\mathrm{NaOH}$ they responded somewhat differently. Aldehyde I, within experimental errors, lost an equimolar amount of formaldehyde and gave linear pseudo first-order plots. Similar plots for compounds II and III were curved in a way which indicated that an equilibrium was reached when slightly less than an equimolar amount of formaldehyde had been formed. In Fig. 2, plots from runs with some different compounds are shown. For compound IV the pseudo first-order plots were still more curved, equilibrium being reached at an earlier stage of the reaction.

For compounds I-III rate constants could thus be evaluated graphically from pseudo first-order plots of $\log \left([\mathrm{A}]_{0}-\left[\mathrm{CH}_{2} \mathrm{O}\right]\right)$ against time. Here $[A]_{0}$ is the initial concentration of the starting material and $\left[\mathrm{CH}_{2} \mathrm{O}\right]$ the concentration of formaldehyde at time $t$. Compound IV, 
on the other hand, was found to obey the rate expression:

$$
\begin{aligned}
& -\frac{\mathrm{d}[\mathrm{IV}]}{\mathrm{d} t}=\frac{\mathrm{d}\left[\mathrm{CH}_{2} \mathrm{O}\right]}{\mathrm{d} t}=k_{1}{ }^{\prime}[\mathrm{IV}]-k_{-1}{ }^{\prime}\left[\mathrm{CH}_{2} \mathrm{O}\right] \times \\
& \times\left[\left(\mathrm{CH}_{3}\right)_{2} \mathrm{CHCHO}\right]=k_{1}\left([\mathrm{IV}]_{0}-\left[\mathrm{CH}_{2} \mathrm{O}\right]\right)- \\
& -k_{-1}{ }^{\prime}\left[\mathrm{CH}_{2} \mathrm{O}\right]^{2}
\end{aligned}
$$

This leads to the integrated expression:

$$
\begin{aligned}
& \psi=\frac{1}{\sqrt{1+4 \tau[\mathrm{IV}]_{0}}} \\
& \ln \frac{1+2 \tau\left[\mathrm{CH}_{2} \mathrm{O}\right] /\left(1+\sqrt{1+4 \tau[\mathrm{IV}]_{0}}\right)}{1+2 \tau\left[\mathrm{CH}_{2} \mathrm{O}\right] /\left(1-\sqrt{\left.1+4 \tau[\mathrm{IV}]_{0}\right)}\right.}=k_{1}{ }^{\prime} t \\
& \text { where } \tau=\lim _{t \rightarrow \infty} \frac{[\mathrm{IV}]_{0}-\left[\mathrm{CH}_{2} \mathrm{O}\right]}{\left[\mathrm{CH}_{2} \mathrm{O}\right]^{2}}
\end{aligned}
$$

The pseudo first-order rate constant $k_{1}{ }^{\prime}$ was evaluated from plots of the function $\psi$ against time (Fig. 3). The same type of expression could be used also for aldehydes II and III, but since the experimental value found for $\tau$ was rather uncertain in these cases, the use of pseudo first-order plots was considered more reliable. The difficulty in determining $\tau$-values accurately is due to the fact that the final concentration of formaldehyde reached was

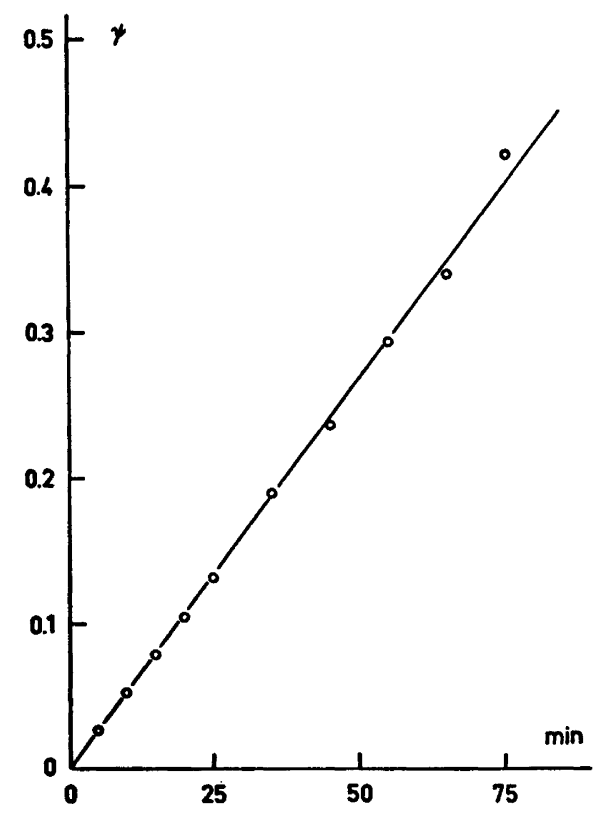

Fig. 3. Experiment with aldehyde IV at $40^{\circ} \mathrm{C}$ in $0.0040 \mathrm{M} \mathrm{NaOH}$ showing function $\psi$ against time. not quite stable with time. On prolonged exposure to the alkaline reaction mixture it showed a tendency to decrease with a few percent, possibly due to oxidation. This was much more critical in the runs with II or III than in those with IV, since, in the former runs, the value of $\left([\mathrm{A}]_{0}-\left[\mathrm{CH}_{2} \mathrm{O}\right]\right)_{\infty}$ was comparatively small.

That equilibria with significant amounts of starting material left were indeed established even in the rather dilute solutions examined, was proven indirectly for compound IV and its products, formaldehyde and isobutyraldehyde. The latter two aldehydes, both $2 \times 10^{-3} \mathrm{M}$, were found to condense rather rapidly at $20^{\circ} \mathrm{C}$. For this reaction a pseudo second-order rate constant, $k_{-1}{ }^{\prime \prime}$, referring to the rate expression:

$$
\begin{aligned}
& -\frac{\mathrm{d}\left[\left(\mathrm{CH}_{3}\right)_{2} \mathrm{CHCHO}\right]}{\mathrm{d} t}=-\frac{\mathrm{d}\left[\mathrm{CH}_{2} \mathrm{O}\right]}{\mathrm{d} t}= \\
& =k_{-1}{ }^{\prime \prime}\left[\left(\mathrm{CH}_{3}\right)_{2} \mathrm{CHCHO}\right][\mathrm{OH}-]=k_{-1}{ }^{\prime \prime}\left[\mathrm{CH}_{2} \mathrm{O}\right]\left[\mathrm{OH}^{-}\right]
\end{aligned}
$$

was obtained from the decrease in formaldehyde concentration. The value calculated from the experimental data was $(5 \pm 2) \times 10^{-2} \mathrm{M}^{-1} \mathrm{~s}^{-1}$. Comparison of this value with the value $5.48 \times 10^{-2} \mathrm{M}^{-1} \mathrm{~s}^{-1}$, obtained earlier for the same reaction in $0.1 \mathrm{M} \mathrm{CH}_{2} \mathrm{O}$ by another method, ${ }^{5}$ shows that, even at the low formaldehyde concentration of $0.002 \mathrm{M}$, the rate of formation of enolate ion from isobutyraldehyde is still probably at least partly rate determining. This was also apparent from plots of the experimental data. The reaction was neither strictly first-order nor second-order in formaldehyde concentration (equal to the concentration of isobutyraldehyde) but something in between. For this reason, the value given above was evaluated graphically from pseudo firstorder plots.

If one tries to calculate a third-order rate constant from the value of $\mathrm{k}_{1}$ " given above, by dividing with the formaldehyde concentration in the run, the value obtained is $25 \pm 10 \mathrm{M}^{-2} \mathrm{~s}^{-1}$. This could be used in conjunction with the value $0.00248 \mathrm{M}^{-1} \mathrm{~s}^{-1}$ for the retro aldol condensation of IV (see Table 2) to calculate the equilibrium constant for the opposed reactions at $20^{\circ} \mathrm{C}$,

$$
K_{\mathrm{IV}}=\frac{\left[\mathrm{CH}_{2} \mathrm{O}\right]\left[\left(\mathrm{CH}_{3}\right)_{2} \mathrm{CHCHO}\right]}{\left[\mathrm{HOCH}_{2} \mathrm{C}\left(\mathrm{CH}_{3}\right)_{2} \mathrm{CHO}\right]}=\frac{k_{1}^{\prime}}{k_{-1}{ }^{\prime \prime \prime}}=\frac{1}{\tau}
$$

Acta Chem. Scand. B 28 (1974) No. 5 
a value of about $10^{-4} \mathrm{M}$ then being obtained. This value is not in agreement with the values of $\tau$ obtained directly from the runs with IV, as these latter values for runs at $20^{\circ} \mathrm{C}$ give $K_{\mathrm{IV}}$-values around $2 \times 10^{-5} \mathrm{M}$. The reason for this discrepancy is obviously that the thirdorder constant calculated above is not a true third-order constant, but was obtained from runs at concentrations of formaldehyde exceeding the concentration at which the reaction is still of first-order with respect to formaldehyde. The $K_{\mathrm{IV}}$-value of $10^{-4} \mathrm{M}$ therefore is too high and values calculated from the $\tau$-values, even though these are rather uncertain, probably are more correct.

From the data in Table 1 a $\Delta H$-value of about $10 \mathrm{kcal} \mathrm{mol}^{-1}$ is obtained for the retro aldol condensation of IV. The difference in activation energies for the retro aldol reaction of IV (see Table 2) and the aldol condensation of isobutyraldehyde with formaldehyde, ${ }^{5}$ on the other hand, amounts to only $19.2-15.1=4.1$ kcal $\mathrm{mol}^{-1}$. If the large uncertainties in the $\tau$-values and also those in the activation energies for the forward and the reverse reactions are

Table 1. Equilibrium constant, $K_{\mathrm{IV}}$, for the retro aldol condensation of 2,2-dimethyl-3hydroxypropanal at different temperatures.

\begin{tabular}{lcccc}
\hline${ }^{\circ} \mathrm{C}$ & 20 & 30 & 40 & 50 \\
\hline$K_{\mathrm{IV}} \times 10^{5} \mathrm{M}$ & 1.7 & 2.8 & 4.7 & 10 \\
\hline
\end{tabular}

taken into account, this discrepancy is still too large and cannot be explained as arising from experimental errors alone. Instead, it must be borne in mind that the activation energies refer to different reaction conditions with respect to formaldehyde concentration and thereby to different rate determining steps for the condensation reaction, as well as to different alkalinities, also at the same nominal concentration of $\mathrm{NaOH}$.

In any case, as apparent from the experimental results, the third-order rate constant for the condensation of isobutyraldehyde with formaldehyde is remarkably large when com. pared with the corresponding constants for the other aldehydes examined. Under comparable conditions the reaction with isobutyraldehyde goes much more nearly to completion. This confirms the conclusion drawn in an earlier paper ${ }^{5}$ concerning the order of reactivity for isobutyraldehyde and some other aldehydes at low formaldehyde concentrations.

The observation that apparently not more than one hydroxymethyl group was split off from aldehydes I-III gave rise to the question as to whether only aldehydes with quaternary substituted $\alpha$-carbons undergo retro aldol condensations of this type with ease. To examine this, the aldehydes, 3-hydroxy-2-hydroxymethylpropanal (V, dimethylolacetaldehyde) and 2,3-dihydroxypropanal (VI, D,L-glyceraldehyde), were subjected to similar treatment. Compound VI, on $5 \mathrm{~h}$ treatment with $0.05 \mathrm{M}$ $\mathrm{NaOH}$ at $20^{\circ} \mathrm{C}$, lost only about $3 \%$ of the

Table 2. Second-order rate constants and activation energies for loss of one equivalent of formaldehyde from various compounds.

\begin{tabular}{|c|c|c|c|c|c|c|c|c|c|}
\hline $\begin{array}{l}\text { Com- } \\
\text { pound }\end{array}$ & $20^{\circ} \mathrm{C}$ & $25^{\circ} \mathrm{C}$ & $\begin{array}{l}k \mathrm{M}^{-1} \mathrm{~s} \\
30^{\circ} \mathrm{C}\end{array}$ & $\begin{array}{c}-1 \text { at v8 } \\
35^{\circ} \mathrm{C}\end{array}$ & $\begin{array}{l}40^{\circ} \mathrm{C} \\
\text { ous temp }\end{array}$ & $\begin{array}{c}\text { ratures } \\
45^{\circ} \mathrm{C}\end{array}$ & $50^{\circ} \mathrm{C}$ & $55^{\circ} \mathrm{C}$ & $\begin{array}{l}E_{\mathrm{A}} \\
\text { kcal } \mathrm{mol}^{-1}\end{array}$ \\
\hline I & 0.302 & & 0.740 & & 1.71 & & & & 15.8 \\
\hline II & 0.0640 & & 0.163 & & 0.407 & & & & 16.9 \\
\hline III & 0.0520 & & 0.134 & & 0.336 & & & & 17.0 \\
\hline IV & 0.00248 & & 0.00750 & & 0.0208 & & 0.0529 & & 19.2 \\
\hline VIII & & 0.00106 & & & 0.00571 & & & 0.0248 & 20.4 \\
\hline IX & & 0.0827 & & & 0.313 & & & 1.02 & 16.3 \\
\hline $\mathbf{X}$ & & 0.040 & & & 0.17 & & & 0.70 & 18.6 \\
\hline XI & & 0.00949 & & & 0.0456 & & & 0.184 & 19.2 \\
\hline XII & & 0.266 & & 0.801 & & 2.15 & & 5.04 & 19.1 \\
\hline XIII & 7.68 & & 19.3 & & 42.5 & & & & 15.6 \\
\hline XIV & 2.51 & & 6.83 & & 17.2 & & & & 17.6 \\
\hline $\mathrm{XV}$ & & 5.76 & & 14.5 & & 33.8 & & & 16.7 \\
\hline XVI & 0.954 & & 2.51 & & 6.14 & & & & 17.0 \\
\hline
\end{tabular}


theoretical amount of formaldehyde. Compound $\mathrm{V}$ released formaldehyde slowly, about 0.5 equiv. after $2 \mathrm{~h}$ and about 0.8 after $24 \mathrm{~h}$ at $40^{\circ} \mathrm{C}$ in $0.01 \mathrm{M} \mathrm{NaOH}$. Some observations in connection with this latter reaction indicated, however, that formaldehyde here was produced as the result of a different reaction sequence. This motivates a separate discussion in a forthcoming paper. Although the number of aldehydes examined is rather small, the experimental data indicate that, of the aldehydes of the type investigated, those with a tertiary $\alpha$-carbon atom lose formaldehyde much more slowly than those with a quaternary $\alpha$-carbon atom.

In order to further investigate the scope of this retro aldol condensation type, some representatives of other classes of compounds were also examined. Of the ketones investigated, 4-hydroxy-3-methyl-2-butanone (VII, monomethylol methyl ethyl ketone) and 4-hydroxy3-hydroxymethyl-3-methyl-2-butanone (VIII, dimethylol methyl ethyl ketone) are examples of simple aliphatic ketones and 3-hydroxy-2hydroxymethyl-2-methyl-1-phenyl-1-propanone (IX, dimethylol propiophenone), 2,2-bis(hydroxymethyl)-1-indanone (X), and 2,2-bis(hydroxymethyl)-1-tetralone (XI) represent mixed aliphatic-aromatic types. 2,3-Dihydroxy-1,2diphenyl-1-propanone (XII, hydroxymethylbenzoin) is structurally similar to aldehyde VI.

Again, the aliphatic compound with tertiary $\alpha$-carbon, VII, was found to resist degradation and remained unchanged after $3 \mathrm{~h}$ in $0.01 \mathrm{M}$ $\mathrm{NaOH}$ at $40^{\circ} \mathrm{C}$. The other five ketones, by contrast, all underwent retro aldol condensation. Three of them, namely compounds VIII, $\mathrm{XI}$, and XII, gave linear pseudo first-order plots of $\log \left([\mathrm{A}]_{0}-\left[\mathrm{CH}_{2} \mathrm{O}\right]\right)$ against time. For compounds IX and $X$, however, such plots were curved in a way indicating that more than one equivalent of formaldehyde was formed

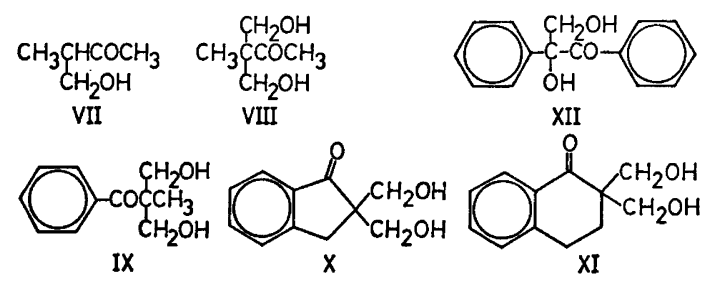

Fig. 4.

Acta Chem. Scand. B 28 (1974) No. 5 from the starting material. This was also evident from the total amount of formaldehyde determined after prolonged exposure to the alkaline reaction conditions. It is thus no general rule that the loss of the first and of the second of two $\alpha$-hydroxymethyl groups occurs with so widely differing rates, that the reactions always can be well-distinguished kinetically (example in Fig. 2).

Compound XII was found to dissolve only with great difficulty in water and was therefore first dissolved in a small amount of methanol, the stock solution then being made up by dilution with water. This caused the presence of about $0.5 \%$ of methanol as solvent in the reaction mixtures. The values obtained from these runs are therefore not strictly comparable with those from runs with the other compounds, since the methoxide ion present in equilibrium with hydroxide ion is possibly a more potent catalyst. General base catalysis should only be observed, however, if the first reaction step, that is the formation of an alkoxide ion, is rate determining, and that is probably not the case.

It is interesting to note that of the two closely similar compounds $\mathrm{X}$ and $\mathrm{XI}$, the retro aldol condensation product from the latter seemed stable under conditions where that of the former lost more formaldehyde. Ketone IX, with a more flexible carbon side chain, also lost more than an equimolar amount of formaldehyde. It is tempting to assume that this has something to do with the spatial arrangements in compounds IX-XI. Thus, in both compounds IX and $X$, there is a greater possibility for the unsaturated system of the enolate ion arising by loss of formaldehyde from the initially formed alkoxide ion to be coplanar than in the corresponding ion from compound $X I$. One may object, that this does not hinder compound XI from first losing a molecule of formaldehyde. The rate of this reaction, however, is lower for compound XI than for the others, and the activation energy is higher. Relatively small differences may be sufficient to slow down the rate of the second retro aldol reaction in the case of XI to a level where this reaction is no longer detectable under the experimental conditions used.

For all the aldehydes and ketones for which rates of reaction were determined (see Table 2), 


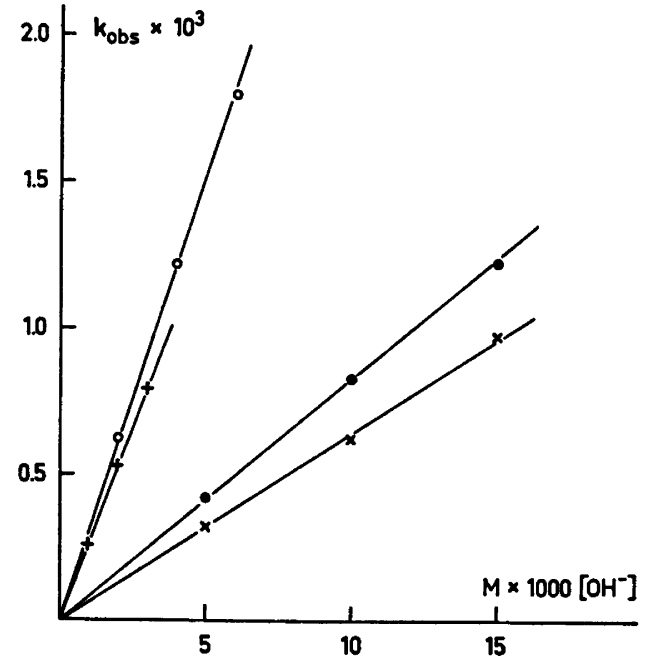

Fig. 5. Pseudo first-order rate constant observed for aldehydes I $(O)$ and II $(x)$ at $20^{\circ} \mathrm{C}$ and ketones IX (O) and XII ( + ) at $25^{\circ} \mathrm{C}$.

these rates were found to be directly proportional to the hydroxide ion concentration, as illustrated in Fig. 5.

Hydroxymethyl-substituted nitro compounds, available by the Henry reaction, are also known to undergo retro aldol type reactions. ${ }^{6}$ The rates of these reactions for the nitro analogs of compounds I-IV, 2-hydroxymethyl-2-nitro1,3-propanediol (XIII, tris(hydroxymethyl)nitromethane), 2-methyl-2-nitro-1,3-propanediol (XIV, bis(hydroxymethyl)nitroethane), 2-ethyl2-nitro-1,3-propanediol (XV, bis(hydroxymethyl)nitropropane), and 2-methyl-2-nitro-1-propanol (XVI), have now been determined (compounds in Fig. 6).

The reactions proceeded rapidly to begin with, but then slowed down as seen from pseudo first-order plots. In these cases this could not be explained by equilibria being attained between starting material and product.

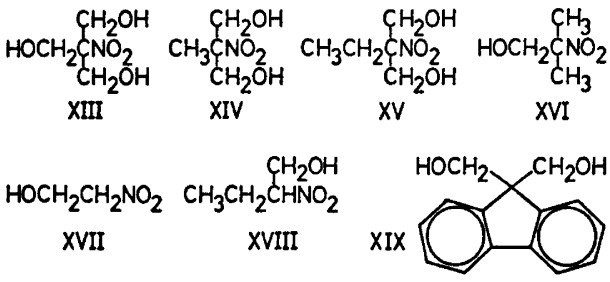

Fig. 6.
This was evident from the results of runs with varying concentrations of the catalyst, $\mathrm{NaOH}$, more formaldehyde being formed if more $\mathrm{NaOH}$ was added. When equimolar amounts of nitro compound and $\mathrm{NaOH}$ were used, the reactions were found to follow the secondorder rate expression (C denoting the nitro compound):

$$
\begin{aligned}
& -\frac{\mathrm{d}[\mathrm{C}]}{\mathrm{d} t}=\frac{\mathrm{d}\left[\mathrm{CH}_{2} \mathrm{O}\right]}{\mathrm{d} t}=k[\mathrm{C}][\mathrm{OH}-]= \\
& =k\left([\mathrm{C}]_{0}-\left[\mathrm{CH}_{2} \mathrm{O}\right]\right)^{2}
\end{aligned}
$$

These findings indicated that hydroxide ion actually was consumed during the reaction. The carbanion formed after loss of the formaldehyde molecule apparently was relatively stable under the reaction conditions, due to resonance involving the nitro group, and therefore did not react with water with regeneration of the catalyst:

$$
\begin{aligned}
& \mathrm{HO}^{-}+\mathrm{HOCH}_{2} \mathrm{CR}_{2} \mathrm{R}_{b} \mathrm{NO}_{2} \rightleftharpoons \\
& \mathrm{H}_{2} \mathrm{O}+-\mathrm{OCH}_{2} \mathrm{CR}_{\mathrm{a}} \mathrm{R}_{\mathrm{b}} \mathrm{NO}_{2}
\end{aligned}
$$

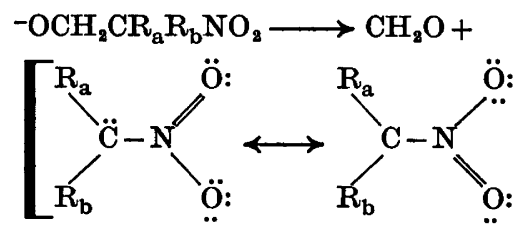<smiles>[R2]C([R2])N([O-])[O-]</smiles>

Second-order plots from experimental runs with compound XV are shown in Fig. 7.

Two compounds with nitro groups on less substituted carbons, 2-nitroethanol (XVII) and 2-nitro-1-butanol (XVIII), were also examined. They lost only relatively small amounts of formaldehyde during one hour at $45^{\circ} \mathrm{C}$ in $3 \times 10^{-4} \mathrm{M} \mathrm{NaOH}$, conditions under which the others reacted rather fast. No further determinations were made.

Finally, one hydroxymethyl-substituted hydrocarbon, 9,9-bis(hydroxymethyl)fluorene (XIX), was studied, but was found to be almost stable in $0.2 \mathrm{M} \mathrm{NaOH}$ at $55^{\circ} \mathrm{C}$ for some hours.

The experimental results, in the form of rate constants and Arrhenius activation energies, are summarized in Table 2.

Acta Chem. Scand. B 28 (1974) No. 5 


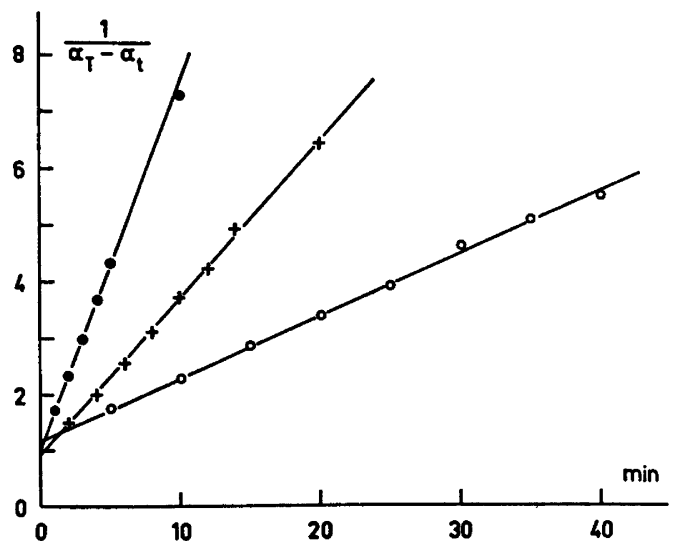

Fig. 7. Second-order plots from runs with nitro compound $\mathrm{XV}$ in $3 \times 10^{-4} \mathrm{M} \mathrm{NaOH}$ at $25^{\circ} \mathrm{C}(\mathrm{O}), 35^{\circ} \mathrm{C}(+)$, and $45^{\circ} \mathrm{C}(O)$, respectively $\left(\alpha_{T}\right.$ and $\alpha_{t}$ as in Fig. 2$)$.

As seen from this table, of the compounds investigated, those activated by a nitro group react much faster than those activated by a carbonyl group. Of the latter compounds, the aliphatic aldehydes apparently react considerably faster than their ketonic analogs, as confirmed by the rate constants for the couple II and VIII. The electron attracting aromatic rings in the ketones IX and $\mathrm{X}$ activate these compounds to rates on a level with those of aldehydes II and III, whereas ketone XI is comparable in reactivity with aldehyde IV. As mentioned previously, the values for compound XII may not be strictly comparable with those for the other compounds, but it is evident that the second aromatic ring has a further activating effect.

The Arrhenius activation energies vary from $15.6 \mathrm{kcal} \mathrm{mol}^{-1}$ for compound XIII to 20.4 kcal mol-1 for compound VIII. Of the structurally related compounds II, VIII, and XIV, the aldehyde and the nitro compound have comparable activation energies, while the ketone has a distinctly higher one. The difference in rate constants between II and VIII roughly corresponds to their difference in activation energies. Nitro compound XIV, on the other hand, reacts considerably faster, which shows, that for this and the other nitro compounds, other factors contribute to facilitate their reactions.

While the limits of error for the activation energies of all the compounds appearing in
Table 2, with the exception of compound X, are thought to be reliable within about $\pm \mathbf{0 . 5}$ $\mathrm{kcal} \mathrm{mol}{ }^{-1}$, the value for this latter compound has an uncertainty of at least twice this value. Rate constants given are normally based on mean values from at least two runs and in several cases from as many as six to ten runs. They were most often reproducible within $\pm 5 \%$, but for compound $X$ they were more scattered.

\section{EXPERIMENTAL}

Materials. Aldehydes I, II, and III were prepared as described in an earlier paper.? A stock solution of aldehyde $\mathrm{V}$ was prepared by hydrolysis of its diethyl acetal on an acid ion exchanger. ${ }^{8}$ Aldehyde IV was prepared by the method of Späth and v. Szilágyi ${ }^{\circ}$ (m.p. $87-88^{\circ} \mathrm{C}$; lit. ${ }^{\circ} 88-89^{\circ} \mathrm{C}$ ). Aldehyde VI (m.p. $130-132^{\circ} \mathrm{C}$; lit. $.^{10} 131-132^{\circ} \mathrm{C}$ ) and nitro com. pounds XIII (m.p. $175^{\circ} \mathrm{C}$; lit..$^{11} 174^{\circ} \mathrm{C}$ ), XIV (m.p. $154-156^{\circ} \mathrm{C}$; lit. $.^{2} 149-150^{\circ} \mathrm{C}$ ), XV (m.p. $55-57^{\circ} \mathrm{C}$; lit..$^{\circ 2} 56^{\circ} \mathrm{C}$ ), XVI (m.p. $90-91{ }^{\circ} \mathrm{C}$; lit. $^{13} 90-91^{\circ} \mathrm{C}$ ), XVII (b.p. ${ }_{0.5} 60^{\circ} \mathrm{C}$; lit..$^{14}$ b.p. ${ }^{\circ}$, $63^{\circ} \mathrm{C}$ ), and XVIII (b.p. ${ }_{10} 105^{\circ} \mathrm{C}$; lit. ${ }^{12}$ b.p. ${ }_{10}$ $105^{\circ} \mathrm{C}$ ) were commercial chemicals. Of these compounds, XIII-XVI were recrystallized from water to reach the melting points listed, while the others were used as received. All ketones and the substituted fluorene were kindly put to the author's disposal by Dr. B. Wesslén. They had the following physical constants: VII (b.p.15 $93-95^{\circ} \mathrm{C}$; lit..$^{15}$ b.p. $89-90^{\circ} \mathrm{C}$ ), VIII (m.p. $62-63^{\circ} \mathrm{C}$; lit. ${ }^{18} 63^{\circ} \mathrm{C}$ ), IX (m.p. 95-97 ${ }^{\circ} \mathrm{C}$ ), lit. $^{17} 96-97^{\circ} \mathrm{C}$ ), $\mathrm{X}$ (m.p. 92-93 ${ }^{\circ} \mathrm{C}$; lit. $.^{18} 92-93^{\circ} \mathrm{C}$ ), XI (m.p. 93-94 ${ }^{\circ} \mathrm{C}$; lit. $93-94^{\circ} \mathrm{C}$ ), XII (m.p. $85-86^{\circ} \mathrm{C}$; lit..$^{10}$ $85-86^{\circ} \mathrm{C}$ ), and XIX (m.p. $144-145^{\circ} \mathrm{C}$; lit. ${ }^{20}$ $\left.145.5-146.5^{\circ} \mathrm{C}\right)$. Acetylacetone of commercial grade was redistilled before use. $\mathrm{NaOH}$ stock solutions were prepared from Merck Titrisol ampoules by dilution with $\mathrm{CO}_{2}$-free, distilled water and were never used for more than a week.

Apparatus. Vis-spectra and absorption measurements were made partly with a Beckman DK 2A istrument and partly with an Unicam SP 800 instrument. Quartz cells of $1.000 \mathrm{~cm}$ length were used throughout the investigation.

General procedure. Normally about $0.25 \mathrm{mmol}$ of the compound to be examined was weighed, introduced into a $100 \mathrm{ml}$ volumetric flask, and dissolved by addition of boiled, distilled water to the mark. Compound XII was first dissolved in $5 \mathrm{ml}$ of methanol before dilution to the mark with water. For each run, $10 \mathrm{ml}$ of the stock solution was taken, introduced into a $100 \mathrm{ml}$ volumetric flask, diluted as much as possible, allowing for later addition of the catalyst, and thermostatted in a water bath to the desired temperature $\pm 0.05^{\circ} \mathrm{C}$. From a

Acta Chem. Scand. B 28 (1974) No. 5 
$\mathrm{NaOH}$ stock solution, kept in the same thermostatted bath, the proper amount of catalyst was taken and the reactions were started by introduction of the latter into the reaction mixture followed by dilution to the mark with thermostatted, distilled water. At regular time intervals, often every fifth minute but sometimes as frequently as every 60 seconds, $4.0 \mathrm{ml}$ samples were taken. They were immediately neutralized by introduction into $10 \mathrm{ml}$ volumetric flasks containing about 0.25 to $0.5 \mathrm{ml}$ of $\mathrm{H}_{2} \mathrm{SO}_{4}$ of the molarity required. To the samples, now slightly acid, were added $5 \mathrm{ml}$ of the aqueous reagent described by Nash,4 containing $150 \mathrm{~g}$ of $\mathrm{NH}_{4} \mathrm{OAc}, 3 \mathrm{ml}$ of glacial acetic acid and $2 \mathrm{ml}$ of redistilled acetylacetone per 1. After dilution to $10.0 \mathrm{ml}$ with water, the solutions were heated 5 to $8 \mathrm{~min}$ at $58^{\circ} \mathrm{C}$. The absorbances of the resulting yellow solutions were then measured at $412 \mathrm{~nm}$. To ensure that the absorbances were not changed due to other Vis-absorbing species in the reaction mixtures, spectra were always run between 360 and $450 \mathrm{~nm}$.

Catalyst concentration ranges. With compound I: $0.002-0.006 \mathrm{M}$; II: $0.005-0.015 \mathrm{M}$; III: $0.005-0.015 \mathrm{M}$; IV: $0.004-0.040 \mathrm{M} ; \mathrm{V}: 0.010 \mathrm{M}$; VI: $0.050 \mathrm{M}$; VII: $0.010 \mathrm{M}$; VIII: $0.050-0.400$ M; IX: $0.001-0.010 \mathrm{M}$; X: $0.0025-0.020 \mathrm{M}$; XI: $0.003-0.030 \mathrm{M}$; XII: $0.0002-0.0030 \mathrm{M}$; XIII-XVIII: $0.0003 \mathrm{M}$; XIX: $0.20 \mathrm{M}$.

Temperature ranges used are evident from Table 2.

Acknowledgements. Generous financial support from The Swedish Board for Technical Development and from Perstorp AB, Perstorp, Sweden, is gratefully acknowledged. The author is indebted to Professor Erich Adler for his kind help and to Dr. Per Flodin for his encouraging support. Mrs. Marianne Frantsi, Mrs. Ulla-Britt Persson, and Mr. Kurt Johnsson are thanked for their skilled and careful laboratory assistance.

\section{REFERENCES}

1. Nielsen, A. T. and Houlihan, W. J. Org. React. 16 (1968) 7.

2. Noyce, D. S. and Snyder, L. R. J. Amer. Chem. Soc. 81 (1959) 624.

3. Dubois, J. E. and Viellard, H. Tetrahedron Lett. (1964) 1809.

4. Nash, T. Biochem. J. 55 (1953) 416.

5. Vik, J.-E. Acta Chem. Scand. 26 (1972) 3165.

6. Unrau, A. M. Can. J. Chem. 42 (1964) 1741.

7. Vik, J.-E. Acta Chem. Scand. 27 (1973) 239.

8. Vik, J.-E. Acta Chem. Scand. 27 (1973) 251.

9. Späth, E. and v. Szilágyi, I. Ber. Deut. Chem. Ges. 76 (1943) 949.

10. Gresham, W. F. and Grigsby, W. E. J. Org. Chem. 14 (1949) 1103.

11. Charlton, W. and Kenner, J. J. Chem. Soc. (1932) 750.
12. Vanderbilt, B. M. and Hass, H. B. Ind. Eng. Chem. 32 (1940) 34.

13. Gabriel, C. L. Ind. Eng. Chem. 32 (1940) 887.

14. Levy, N., Scaife, C. W. and Wilder-Smith, A. E. J. Chem. Soc. (1946) 1096.

15. Morgan, G. T. and Holmes, E. L. J. Chem. Soc. (1932) 2670.

16. Décombe, J. C. R. Acad. Sci. Ser. C 203 (1936) 1077.

17. Manta, J. J. Prakt. Chem. 142 (1935) 11.

18. Wesslén, B. Acta Chem. Scand. 21 (1967) 713.

19. Kusin, A. Ber. Deut. Chem. Ges. 68 (1935) 2169.

20. Ghera, E. and Sprinzak, Y. J.Amer. Chem. Soc. 82 (1960) 4945.

Received January 10, 1974. 